\title{
World Journal of Pediatric Surgery \\ Needs assessment of parents for a patient decision aid in pediatric interval appendectomy via the qualitative interview method
}

Viviane Grandpierre, ${ }^{1}$ Katherine Duba, ${ }^{2}$ Karine Toupin April, ${ }^{3}$ Irina Oltean, ${ }^{1}$ Arielle Weir, ${ }^{1}$ Ahmed Nasr ${ }^{1}$

To cite: Grandpierre V, Duba K, Toupin April K, et al. Needs assessment of parents for a patient decision aid in pediatric interval appendectomy via the qualitative interview method. World Jnl Ped Surgery 2022;5:e000371. doi:10.1136/ wjps-2021-000371

Received 13 September 2021 Accepted 15 December 2021

Check for updates

(c) Author(s) (or their employer(s)) 2022. Re-use permitted under CC BY-NC. No commercial re-use. See rights and permissions. Published by BMJ.

${ }^{1}$ Surgery, Children's Hospital of Eastern Ontario, Ottawa, Ontario, Canada

${ }^{2}$ Biology, Clarkson University, Potsdam, New York, USA ${ }^{3}$ Pediatrics, University of Ottawa, Ottawa, Ontario, Canada

Correspondence to Dr Ahmed Nasr, Surgery, Children's Hospital of Eastern Ontario, Ottawa, Ontario, Canada; anasr@cheo.on.ca

\section{ABSTRACT}

Objectives Appendicitis is one of the most commonly encountered pediatric surgical diagnoses, with nonoperative management of perforated appendicitis leading to two treatment options: an interval appendectomy (IA) or expectant management. The primary objective of this study was to assess parents' need for a patient decision aid (PDA) among parents considering IA or expectant management. A secondary objective was to determine parent preferences for the format and distribution plan of a drafted patient decision aid.

Methods Coulter's systematic development process for PDA was used to guide the assessment interviews for parents. Participants included caregivers of a patient who experienced perforated appendicitis, and admission between 2019 and 2020. Semi-structured individual interviews were conducted to collect information about decision-making needs of parents of children who experienced perforated appendicitis.

Results A total of 12 different parents participated in the interviews. Results indicate decisional conflict associated with the lack of evidence for optimal treatment, supporting the need for the development of a patient decision aid to assist in clarifying information and parent values with practitioners. Parents clearly identified a need for evidence to support decision-making in various formats (eg, pamphlet or electronic). Timing of when to deliver the PDA varied (ie, during hospital admission, at discharge, or at follow-up appointment).

Conclusion Results indicated various factors contributing to parental decisional conflict, including the lack of evidence showing the optimal treatment, the need for more information, and guidance from practitioners. Overall, findings indicate a strong need for a patient decision aid.

\section{INTRODUCTION}

Appendicitis is one of the most commonly encountered pediatric surgical diagnoses, ${ }^{1-7}$ with over $30 \%$ of children presenting with perforation. ${ }^{4} 8$ Successful non-operative management of pediatric perforated appendicitis typically leads to two treatment options: an interval appendectomy (IA) or expectant management, where the appendix

\section{WHAT IS ALREADY KNOWN ABOUT THIS SUBJECT?}

$\Rightarrow$ Appendicitis is one of the most commonly encountered pediatric surgical diagnoses.

$\Rightarrow$ Successful non-operative management of pediatric perforated appendicitis typically leads to two treatment options: an interval appendectomy (IA) or expectant management.

$\Rightarrow$ Parents face decisional conflict on whether or not to have their child undergo elective IA.

\section{WHAT ARE THE NEW FINDINGS?}

$\Rightarrow$ Parents explained that they required additional evidence regarding the optimal treatment for their family, the need for more information, and further clarification and guidance from practitioners.

$\Rightarrow$ Findings suggest a need for a patient decision aid at our institution.

$\Rightarrow$ A subsequent pilot study will be conducted to evaluate the effectiveness of a newly developed draft patient decision aid.

\section{HOW MIGHT IT IMPACT CLINICAL PRACTICE IN THE FORESEEABLE FUTURE?}

$\Rightarrow$ At our institution, the integration of a patient decision aid to assist parents in deciding the optimal treatment option for their child may be encouraged.

$\Rightarrow$ Current findings will inform the design and implementation of the draft patient decision aid study.

$\Rightarrow$ Future institutions may consider the design and facilitation of a patient decision aid, to assist parents in deciding the optimal treatment option for pediatric perforated appendicitis.

is only removed if symptoms of appendicitis recur. Both options carry relatively low risks, and neither has been proven superior. ${ }^{9-11}$ In cases where there are multiple viable treatments, decision-making can be difficult, especially among pediatric patients. Decision-making regarding elective IA is often left to the discretion of children's caregivers' preferences in North America, as 
both management approaches have similar rates of low complications. ${ }^{12}$

Parents facing the decision of whether or not to have their child undergo elective IA may face decisional conflict. For example, at our institution there are many instances where parents express decisional conflict regarding this elective procedure. Decisional conflict is defined as when an individual experiences uncertainty regarding a particular course of action where the options involve high stakes. ${ }^{13}$ Decisional conflict can increase when decision-makers feel uninformed and experience a lack of clarity regarding their own personal values, experience social pressure regarding a particular course of action, and feel minimal confidence regarding their own decision-making ability. ${ }^{14}$ As a result, parents may experience emotional distress that can lead to indecisiveness, delayed decision-making, and decisional regret. ${ }^{15} 16$

Shared decision-making (SDM) may facilitate valuebased informed decision-making, thereby potentially reducing decisional conflict. ${ }^{17} \mathrm{SDM}$ is a collaborative model of healthcare decision-making in which children, their parents, and their healthcare provider work together to reach a mutual decision about tests, treatments, or care plans. ${ }^{18}$ SDM is particularly important in cases of 'preference-sensitive' decisions, where more than one reasonable option exists and there is a difference between how individuals weigh the risks and benefits of each option in terms of their personal values and preferences. ${ }^{19}$ Additionally, there is growing evidence that parents and their children prefer to be involved in treatment decision-making. ${ }^{19-21}$

SDM interventions can help to facilitate this process. Among these, patient decision aids (PDAs) are evidencebased tools that can help to prepare for SDM typically among parents facing difficult decisions and their healthcare providers. The use of PDAs has been shown to improve knowledge of the available options, allowing parents to feel more informed and clear about what matters most to them and giving them more accurate expectations of possible benefits and harms. ${ }^{22}$ Recent PDA developers have engaged multiple patient and healthcare provider stakeholders in the design, development, and testing of PDAs as recommended by shared decision-making experts. ${ }^{23}{ }^{24}$ PDAs have been developed for a variety of adult and pediatric medical and surgical conditions. However, there are very few PDAs for pediatric surgery, despite the fact that a number of common pediatric surgical conditions exist where optimal management is not always clear.

Based on our experience, parents considering elective IA would benefit from SDM. For example, we recently attempted to carry out a randomized controlled trial to compare IA and conservative management. However, recruitment was very low, indicating that parents are not comfortable with the treatment decision being made for their child (randomization) and prefer to be involved in the decision-making process. Also, many parents still delay the decision or make comments that indicate decisional conflict, such as mentioning things like "I am worried that if we do nothing, the appendicitis will come back, but I am scared of my child having surgery". For these reasons, we believe an SDM intervention, such as a PDA, is needed for parents, with consideration of parental decision-making needs.

Thus, the primary objectives of this study were to assess the decision-making needs of parents considering elective IA for their child and to determine the need for a patient decision aid. The secondary objective was to determine parent preferences regarding the format and distribution plan of a drafted PDA.

If there is a need for a PDA, it could be the first decision aid developed as part of the Canadian Association of Paediatric Surgeons (CAPS) Decision Aids Project. Our research team collaborates with CAPS to produce the CAPS Evidence-Based Resource (CAPS EBR), ${ }^{25}$ which provides summaries of the best available evidence on a variety of pediatric surgical topics. The corresponding author's team produces these summaries by reviewing the scientific literature (ie, systematic reviews), which is an essential step in the development of a PDA. Furthermore, when the results of the systematic reviews for the CAPS EBR reveal clinical equipoise for a condition where it is appropriate for children and their families to be involved in SDM, a needs assessment for a PDA will follow.

This study took place at the Children's Hospital of Eastern Ontario (CHEO), a tertiary care hospital located in Ottawa, the capital city of Canada. Healthcare is covered under the Canada Health Care Act (eg, hospital stays that are medically necessary).

\section{METHODS}

\section{Framework}

The systematic development process for PDA by Coulter et $a l^{24}$ was used to guide the decision-making needs assessment interviews for parents of children with perforated appendicitis.

\section{Steering committee}

A steering group was assembled to assist with the needs assessment. The steering committee assisted in the development of appropriate and acceptable interview guides for parents and in analysis of the interview content. Parents who made the decision of whether to undergo IA were approached to join the committee.

Three such parents who received services at the Children's Hospital of Eastern Ontario were recruited to participate in the steering group. The committee also included a multidisciplinary team of content experts (four pediatric surgeons specializing in general surgery and two registered nurses from ambulatory care and inpatient surgical services in Canada). Additionally, CHEO's Family Advisory Council (FAC) were consulted as stakeholders to oversee the PDA development process. The FAC council included parents whose children have received services from CHEO. The steering committee 
will be involved throughout the development of a PDA, if warranted.

\section{Participants}

Participants were eligible if they were: (a) parents of children (0-18 years of age) or caregivers of a pediatric patient who experienced perforated appendicitis, (b) parents or caregivers of children who were admitted to the surgical ward at CHEO between 2019 and 2020 and and (c) were fluent in either official languages of English or French. Parents of children with additional comorbidities were excluded, in order to receive an accurate representation of the lived experiences from parents of children with solely perforated appendicitis. At CHEO, perforated appendicitis is defined as a visible hole or tear in the appendix, with signs of abscess, phlegmon, or collections.

Recruitment occurred from March 2019 to October 2020. Electronic health records system was monitored for admissions to the surgical ward and surgical day clinic for follow-up appointments postdischarge. Eligible parents were approached by a member within the circle of care and asked if they would be interested in speaking to the lead researchers (VG, AW). Once informed consent had been received, the same researchers arranged and conducted the interviews. Both researchers have extensive experience in clinical qualitative research including interviewing families of sick children. VG has a $\mathrm{PhD}$ in Rehabilitation Sciences, and AW has obtained a PhD in epidemiology. VG and AW did not have any prior relationships with or presuppositions of the parents and approached the interviews in an unbiased, non-leading fashion.

\section{Procedure}

In order to assess if there is a need for a PDA for parents, semi-structured individual interviews were conducted to collect information about decision-making needs of parents of children/youth who experienced perforated appendicitis. The interpretive description (ID) method by Thorne $e t$ al informed recruitment and data collection. ${ }^{26}$ ID uses features of grounded theory, ethnography, and naturalistic inquiry, with the goal of capturing a meaningful account of a clinical phenomenon. According to Thorne $e t a l$, this is achievable by drawing on small samples through methods such as interviews. As such, a convenience sample of 10-12 parents was therefore anticipated to be appropriate for obtaining relevant information, aproviding a clinical snapshot of the population.

The interview protocol included questions regarding parental IA decision-making (eg, if difficult and why), their preferences and values, existing decision support, and what other decision support might help (eg, PDA). A description of a PDA was provided, including formatting (eg, electronic vs paper). During the interview, field notes were taken to note overall impressions or general thoughts about responses. Interviews were conducted by phone and were audio recorded and transcribed verbatim by a professional transcriptionist. Data were entered into NVivo (V.12), a qualitative software program used for coding. Demographic information was entered into Excel.

\section{Analysis}

Transcripts were analyzed using open, axial, and selective coding methods by Corbin and Strauss, a coding process based on the constant comparative method. ${ }^{27}$ Briefly, open coding involves assigning labels to each passage in the transcripts. Characteristics of these labels were then compared between interviews for consistency and to eliminate redundancy in axial coding. The final step is selective coding, whereby labels are reviewed for similarities and are then collapsed into major themes. Analysis was performed by the lead author (VG) and was verified by a medical research assistant $(\mathrm{KD})$ who received extensive training in qualitative coding.

\section{Research rigor}

In qualitative research, the concept of trustworthiness ${ }^{28}$ was established to ensure transparency and quality. There are four key components of trustworthiness: credibility, transferability, dependability, and confirmability. We consulted with coauthors (KTA, AN) throughout analysis and interpretation, which established credibility. Transferability was achieved with the provision of in-depth details supported by various quotes. Transparent documentation of the research process ensured dependability. Finally, confirmability was established through the recording and consulting field notes, as well as all coauthors with expertise in qualitative research, pediatric surgery, and health sciences who could audit and validate the interview data entered.

\section{RESULTS}

A total 18 parents or caregivers were approached during the recruitment period. Children aged 12-18 years were not able to participate in the interview because the median age was 6.3 years. One parent declined, stating they were not comfortable with participating. Five parents consented to being contacted, but they did not respond to contact. A total of 12 different parents participated in the interviews (10 mothers and 2 fathers) (table 1$)$.

Seven interviews were conducted a few weeks after initial discharge, and five were interviewed a few weeks after the follow-up appointment (eg, 6 weeks postinitial discharge). Four parents were making the decision, four had made the decision, and the remaining were unsure. The age of the children ranged from 3.7 to 12.9 years. Admission details are listed in table 2.

Several themes emerged from the analysis with parents: need for more information, decisional conflict and its sources, usefulness of a decision aid, and features of a helpful PDA. 
Table 1 Participant characteristics

\begin{tabular}{|c|c|}
\hline Characteristics & $\begin{array}{l}\text { Parents } \\
(n=12)\end{array}$ \\
\hline \multicolumn{2}{|l|}{ Interviewee, n (\%) } \\
\hline Mother only & $10(83.3)$ \\
\hline Father only & $2(16.7)$ \\
\hline \multicolumn{2}{|l|}{ Treatment stage at time of interview, n (\%) } \\
\hline $\begin{array}{l}\text { Child discharged, pre-follow-up } \\
\text { appointment ( }<1 \text { mon) }\end{array}$ & 7 (58.3) \\
\hline Post-follow-up appointment (<2 mon) & $5(41.7)$ \\
\hline \multicolumn{2}{|c|}{ Treatment preference at time of interview, n (\%) } \\
\hline IA & $4(33.3)$ \\
\hline Non-surgical & $4(33.3)$ \\
\hline Unsure & $4(33.3)$ \\
\hline \multicolumn{2}{|l|}{ Languages, n (\%) } \\
\hline English & $11(91.7)$ \\
\hline French & $1(8.3)$ \\
\hline \multicolumn{2}{|l|}{ Children, n (\%) } \\
\hline Male & $5(41.7)$ \\
\hline Female & 7 (58.3) \\
\hline Age in years, median (range) & $6.3(3.7-12.9)$ \\
\hline
\end{tabular}

\section{Need for more information regarding IA}

All parents described experiencing stress during the events leading up to and after admission for perforated appendicitis. During admission, parents were approached by attending surgeons, and told about an optional appendectomy in the future. Nearly all parents $(n=10)$ described not having enough information to make an informed decision regarding the elective surgery:

I definitely feel the need for more information. For sure.-Parent 1

I would have liked [more] information, then, when you first get in there because as you talk to people, then everybody starts giving you their opinions....It's information you could have in the hospital, just so the person knows what it means and what your next steps could be.-Parent 3

I do think [more information would be better] because if you have information, then at least you can

Table 2 Medical information

\begin{tabular}{ll}
\hline Characteristics & $\begin{array}{l}\text { Parents responding } \\
\text { on behalf of children } \\
(\mathbf{n}=12)\end{array}$ \\
\hline Appendicolith on admission, $\mathrm{n}(\%)$ & $3(25.0)$ \\
\hline Initial management, $\mathrm{n}(\%)$ & \\
\hline \multicolumn{1}{|c|}{ Antibiotics } & $7(58.3)$ \\
\hline Antibiotics+peritoneal drainage & $5(41.7)$ \\
\hline
\end{tabular}

base your decision on something. At this point right now, my 6-week follow-up, I'm going in blind and I don't know what other cases have been like and what the likelihood of recurrence is and things like that. So at least if I have something to look at and say, my son falls into category A and the likelihood of it coming back is $1 \%$, then going into that 6-week follow-up at least I'd be able to say I'm willing to take a $1 \%$ chance, or I'm not willing to do that $1 \%$ chance and I want it removed, and at least that way going in knowing what I'm getting into. As opposed to not.-Parent 7

\section{Decisional conflict and its sources}

A total of 10 parents stated how at one point they felt unsure what the best option is because both treatment options have optimal outcomes with minimal risks. Thus, decision support is crucial to assist during the decisionmaking process.

Yeah, we're kind of on the fence at the moment. One of my concerns was if she's got a necrotic organ just lying there, what would that mean long-term and if it would pose a possible problem in the future for her...-Parent 1

But, of course, just understanding the risks of surgery vs the risks of a repeat of the appendicitis and there wasn't the science to necessarily backup the decision. We really wanted to base our decision in the science, but, as was explained to us by the doctor and just our own reading, there wasn't an absolute one way or the other piece of information that could direct us.-Parent 6

At the end of the day, I guess I don't have enough information right now to make that decision. My biggest fear is that what if this happens again, then it's another five days in the hospital, more IV antibiotics, all of that kind of stuff OR if it's easier just to remove it to prevent any future complications or infection of the appendix.-Parent 7

Decisional conflict was influenced by various parental concerns. Parents described 'pros and cons' of both treatment approaches in terms of concerns (table 3).

Regarding surgery, benefits were that surgery would take place in a controlled environment and would help

Table 3 Parents' perceived sources of decisional conflict

\begin{tabular}{llll}
\hline Surgical & & \multicolumn{2}{l}{ Non-surgical } \\
\hline Benefits & Risks & Benefits & Risks \\
$\begin{array}{l}\text { Avoids } \\
\text { recurrence }\end{array}$ & Anesthesia & $\begin{array}{l}\text { No } \\
\text { surgery }\end{array}$ & Recurrence \\
$\begin{array}{l}\text { Controlled } \\
\text { environment }\end{array}$ & Complications & & $\begin{array}{l}\text { No signs of } \\
\text { recurrence }\end{array}$ \\
& $\begin{array}{l}\text { Postoperative } \\
\text { pain and recovery }\end{array}$ & $\begin{array}{l}\text { Repeat } \\
\text { antibiotics }\end{array}$
\end{tabular}


to avoid recurrence. Risks included concerns for anesthesia, surgical complications, and postoperative pain and recovery.

I think we asked about risk of infection and about the anaesthesia and the risk of that. However, I also wanted it taken care of and I like the idea that it was going to scheduled. It was going to be a controlled situation where things were going to be calm, he wasn't going to be upset that he was already in pain or already showing symptoms of it—so that whole factor as opposed to having another emergency situation where just the chaos that that brings as well would make it so much more traumatic for him, and for all of us. So that was definitely a factor [in decision-making] as well.-Parent 6

However, when considering the non-surgical route, parents described risks as concerns for recurrence, missing the signs of recurrence, as well as fear of the effects of repeat antibiotics. Conversely, they described the benefits to taking this route as avoiding surgery.

I guess the other thing is, if he did have another perforation or something were to happen or it became inflamed, what are the risks of being on anotherlike he's been on so many antibiotics. So even if we had to do more intervention with antibiotics, what are the long-term costs or risks of that? What are the risks of if we were to leave the appendix in-how likely would there be a recurrence. What would that recurrence look like? What signs would we be watching for? How quickly would onset be if something were to happen? I guess on the other side, if we were to take the appendix out, when they go in, what are some of the issues that could arise?-Parent 8

\section{Usefulness of a decision aid}

All parents stated a decision aid would be invaluable for future parents in this situation, with most $(n=10)$ expressing how they wished such a tool would have been available to them.

I think because you're often dealing with many different health professionals, having something in front of you, concrete-that even when you're exhausted or kind of overwhelmed-it's easier to have something that you can refer back to that can help you make that decision.-Parent 8

It (PDA) could help a lot with making the decision.Parent 6

I think future parents who are in that same situation could really benefit from helpful weighing out their options.-Parent 1

I feel like it (PDA) would certainly help if somebody's at a crossroads, for sure. I feel like we're at that crossroads where we're kind of debating yay or nay.-Parent 12

\section{Box 1 Useful features of a patient decision aid}

$\Rightarrow$ General information on the condition (eg, prevalence, severity, longterm effects) and prognosis.

$\Rightarrow$ Parent stories of similar experiences and social connections.

$\Rightarrow$ Treatment options (probabilities for risks and benefits).

$\Rightarrow$ Recovery information.

$\Rightarrow$ Symptoms of recurrence.

\section{Useful features of a PDA}

The final theme that emerged was useful features of a PDA for parents/caregivers in this situation (box 1).

The majority of parents $(n=11)$ stated that an overview of risks versus benefits of both treatment options including treatment/recovery timelines would be important to include. This also should include a list of symptoms for possible recurrence. Numerous parents $(n=7)$ wanted this information to include statistics for recurrence and surgical complications. Seven parents talked about how useful it would be to have stories from other parents in the decision aid or to have a link to a platform to discuss treatment options with other families.

Preferences for formatting varied, with a physical pamphlet being the most popular choice, followed by electronic PDF, or an electronic app. Some suggested having helpful visual graphics regarding anatomy and treatments.

Timing of when to deliver of the PDA varied among those who discussed it. Some suggested it would be helpful if it was received at initial discharge $(n=4)$, whereas others felt it would be most appropriate at the follow-up appointment $(n=3)$. Few felt it would be useful during initial admission $(n=2)$, with many saying that they were still processing all that was occurring.

\section{DISCUSSION}

To the best of our knowledge, this study is the first to explore the decision-making needs among parents considering IA for their child with perforated appendicitis. Overall, results indicated parental decisional conflict associated with the lack of information, supporting the need for the development of a PDA to assist in clarifying information and values with practitioners. Parents clearly identified a need for information presented in various manners (eg, via clinicians and support staff and/or evidence-based materials).

Results revealed that many factors influence parental decision-making, such as weighing the benefits versus risks of each treatment, concerns for outcomes, and limited information regarding symptoms of possible recurrence and surgical complications. Because both options carry relatively low risks and neither is proven to be superior, parents often felt unequipped to make the decision. As previously stated, we found similar results when we had to stop a randomized controlled trial (that sought to compare IA and conservative management) due to low recruitment, thus indicating decisional 
conflict. Decision aids used in conjunction with healthcare practitioner interactions have been shown to reduce decisional conflict by increasing knowledge of treatment options and the associated risks versus benefits for each approach. ${ }^{22}{ }^{29}$ The result may help to achieve the desired balance between practitioners' and parents' input. ${ }^{30}$

One notable limitation is the lack of direct child and youth feedback regarding the needs assessment. Children were not able to participate in the interview because the median age was too low. However, parents in the interviews did consult their children regarding treatment preferences, as reflected in the results. It is important to note that children should be included in the development of PDA; however, this study was purely a needs assessment to determine if a PDA is warranted. Data regarding socioeconomic status (SES) were not collected; however, analyzing SES in relation to decision conflict was beyond the scope of this study. Additionally, although the sample size was small, our primary objective was to provide a clinical snapshot of decisional conflict experienced by parents, facing two viable treatment options with low risks for their children. All parents voiced the need for such a tool, stating how it would ease decisional conflict.

The next phase will involve creating a prototype of the PDA that adheres to the International Patient Decision Aid Standards. ${ }^{31}$ Abiding by the procedure for the development of PDAs by Coulter et $a l^{24}$ we will pilot a two-step testing approach, alpha and beta testing. Alpha testing will occur with stakeholders (eg, children and youth, family members, or caregivers, and steering group members) involved in the PDA development process. This will allow the assessment of comprehensibility and usability and will be applicable to the pediatric population most affected by perforated appendicitis. The feedback will be used to revise the PDA accordingly. Beta testing will involve field testing of the PDA using families not involved in its development in 'real-life' situations. Feasibility and satisfaction will also be assessed during the beta testing phase.

In conclusion, this is the first step in developing a PDA in pediatric surgery. Findings provided insight into the decision-making needs of parents of children with perforated appendicitis who are being treated conservatively. Results indicated various factors contributing to parental decisional conflict, such as the lack of evidence showing the optimal treatment, the need for more information, and the need for clarification and guidance from practitioners. Overall, findings indicate a strong need for a PDA for parents deciding on the optimal treatment for their child with perforated appendicitis.

Correction notice This article has been corrected since it first published online. The article type has been updated to 'Original research' in order to better categorise the article content.

Contributors VG contributed to data curation, formal analysis, investigation, methodology, project administration, software, validation, visualization and writing — original draft. KD contributed to investigation, validation and writing review and editing. KTA contributed to investigation, validation and writing-review and editing. 10 contributed to writing - review and editing. AW contributed to project administration, validation and writing - review and editing. AN contributed to conceptualization, data curation, funding acquisition, investigation, methodology and writing — review and editing.

Funding The authors have not declared a specific grant for this research from any funding agency in the public, commercial or not-for-profit sectors.

Competing interests None declared.

Patient consent for publication Not applicable.

Ethics approval The CHEO Research Ethics Board approved this study (CHEOREB\# 16/172X). Participants gave informed consent to participate in the study before taking part.

Provenance and peer review Not commissioned; externally peer reviewed.

Data availability statement Data are available on reasonable request.

Open access This is an open access article distributed in accordance with the Creative Commons Attribution Non Commercial (CC BY-NC 4.0) license, which permits others to distribute, remix, adapt, build upon this work non-commercially, and license their derivative works on different terms, provided the original work is properly cited, appropriate credit is given, any changes made indicated, and the use is non-commercial. See: http://creativecommons.org/licenses/by-nc/4.0/.

\section{REFERENCES}

1 Howell EC, Dubina ED, Lee SL. Perforation risk in pediatric appendicitis: assessment and management. Pediatric Health Med Ther 2018;9:135-45.

2 Blakely ML, Williams R, Dassinger MS, et al. Early vs interval appendectomy for children with perforated appendicitis. Arch Surg 2011;146:660-5.

3 Morrow SE, Newman KD. Current management of appendicitis. Semin Pediatr Surg 2007;16:34-40.

4 Ponsky TA, Huang ZJ, Kittle K, et al. Hospital- and patient-level characteristics and the risk of appendiceal rupture and negative appendectomy in children. JAMA 2004;292:1977-82.

5 Gentleman JF, Vayda E, Parsons GF, et al. Surgical rates in subprovincial areas across Canada: rankings of 39 procedures in order of variation. Can J Surg 1996;39:361.

6 Pearl RH, Hale DA, Molloy M, et al. Pediatric appendectomy. $J$ Pediatr Surg 1995;30:173-81.

7 Willemsen PJ, Hoorntje LE, Eddes E-HH, et al. The need for interval appendectomy after resolution of an appendiceal mass questioned. Dig Surg 2002;19:216-22.

8 Newman K, Ponsky T, Kittle K, et al. Appendicitis 2000: variability in practice, outcomes, and resource utilization at thirty pediatric hospitals. J Pediatr Surg 2003;38:372-9.

9 Chen C, Botelho C, Cooper A, et al. Current practice patterns in the treatment of perforated appendicitis in children. J Am Coll Surg 2003;196:212-21.

10 Hall NJ, Jones CE, Eaton S, et al. Is interval appendicectomy justified after successful nonoperative treatment of an appendix mass in children? A systematic review. J Pediatr Surg 2011;46:767-71

11 Puapong D, Lee SL, Haigh PI, et al. Routine interval appendectomy in children is not indicated. $J$ Pediatr Surg 2007;42:1500-3.

12 Emile SH, Sakr A, Shalaby M, et al. Efficacy and safety of nonoperative management of uncomplicated acute appendicitis compared to appendectomy: an umbrella review of systematic reviews and meta-analyses. World J Surg 2022:1-17.

13 O'Connor AM. Validation of a decisional conflict scale. Med Decis Making 1995;15:25-30.

14 O'Connor AM, Drake ER, Wells GA, et al. A survey of the decisionmaking needs of Canadians faced with complex health decisions. Health Expect 2003;6:97-109.

15 Sun Q. Predicting downstream effects of high decisional conflict: meta-analyses of the decisional conflict scale, 2005. Available: https://ruor.uottawa.ca/handle/10393/27050 [Accessed 10 Feb 2021].

16 Knops AM, Goossens A, Ubbink DT, et al. Interpreting patient decisional conflict scores: behavior and emotions in decisions about treatment. Med Decis Making 2013;33:78-84.

17 Kremer H, Ironson G, Schneiderman N, et al. "It's my body": does patient involvement in decision making reduce decisional conflict? Med Decis Making 2007;27:522-32.

18 Charles C, Gafni A, Whelan T. Shared decision-making in the medical encounter: what does it mean? (or it takes at least two to tango). Soc Sci Med 1997;44:681-92. 
19 Dreesens D, Veul L, Westermann J, et al. The clinical practice guideline palliative care for children and other strategies to enhance shared decision-making in pediatric palliative care; pediatricians critical reflections. BMC Pediatr 2019;19:467.

20 Hsiao JL, Evan EE, Zeltzer LK. Parent and child perspectives on physician communication in pediatric palliative care. Palliat Support Care 2007;5:355-65.

21 Zwaanswijk M, Tates K, van Dulmen S, et al. Young patients', parents', and survivors' communication preferences in paediatric oncology: results of online focus groups. BMC Pediatr 2007;7:35-45.

22 Stacey D, Légaré F, Lewis K, et al. Decision AIDS for people facing health treatment or screening decisions. Cochrane Database Syst Rev 2017;4:CD001431.

23 Wysocki T, Hirschfeld F, Miller L, et al. Consideration of insulin pumps or continuous glucose monitors by adolescents with type 1 diabetes and their parents: stakeholder engagement in the design of web-based decision AIDS. Diabetes Educ 2016;42:395-407.

24 Coulter A, Stilwell D, Kryworuchko J, et al. A systematic development process for patient decision AIDS. BMC Med Inform Decis Mak 2013;13 Suppl 2:S2
25 Surgeons. CA of P. Canadian association of paediatric surgeons evidence-based resource, 2019. https://www.caps.ca/

26 Thorne S, Kirkham SR, MacDonald-Emes J. Interpretive description: a noncategorical qualitative alternative for developing nursing knowledge. Res Nurs Health 1997;20:169-77.

27 Corbin J, Strauss A. Basics of qualitative research: techniques and procedures for developing grounded theory. Thousand Oaks: Sage Publications, Inc, 2008.

28 Krefting L. Rigor in qualitative research: the assessment of trustworthiness. Am J Occup Ther 1991;45:214-22.

29 Coxeter PD, Del Mar CB, Hoffmann TC. Preparing parents to make an informed choice about antibiotic use for common acute respiratory infections in children: a randomised trial of brief decision AIDS in a hypothetical scenario. Patient 2017;10:463-74.

30 Knops AM, Legemate DA, Goossens A, et al. Decision AIDS for patients facing a surgical treatment decision: a systematic review and meta-analysis. Ann Surg 2013;257:860-6.

31 Elwyn G, O'Connor AM, Bennett C, et al. Assessing the quality of decision support technologies using the International patient decision aid standards instrument (IPDASi). PLoS One 2009; 4:e4705. 